\title{
Metoclopramide and pimozide in Parkinson's disease and levodopa-induced dyskinesias
}

\author{
DANIEL TARSY, J. DAVID PARKES, AND C. DAVID MARSDEN \\ From the University Department of Neurology, Institute of Psychiatry, and King's College Hospital, \\ London, and the Department of Neurology, Boston University School of Medicine, Boston, \\ Massachusetts, U.S.A.
}

SYNOPSIS Metoclopramide is an antiemetic drug which occasionally produces acute dystonic reactions. Although known to interfere with central dopamine mechanisms, it is frequently used in Parkinson's disease to prevent levodopa-induced nausea and vomiting. In this study metoclopramide did not increase Parkinsonism or reduce levodopa-induced involuntary movements in patients with Parkinson's disease. Pimozide, by contrast, increased Parkinsonism and reduced involuntary movements. The capacity of metoclopramide to produce acute dyskinesias while being apparently free of Parkinsonism effects is pharmacologically unique and differentiates this drug from the phenothiazines and butyrophenones.

Metoclopramide (4-amino-5-chloro-N-[2(diethylamino)ethyl]-o-anisamide hydrochloride) is a non-phenothiazine antiemetic drug which inhibits vomiting caused by either centrallyacting emetics such as apomorphine or local emetics acting on the stomach (Justin-Besançon and Laville, 1964; Laville, 1964; Malméjac et al., 1964). Metoclopramide also appears to speed gastric emptying by a direct action within smooth muscle (Jacoby and Brodie, 1967). As a result, metoclopramide has been introduced as an antiemetic for a wide range of gastrointestinal disorders and as an aid to radiological study of the gastrointestinal tract (Robinson, 1973a).

While used as an antiemetic, metoclopramide has been reported to produce acute dystonic reactions in approximately $1 \%$ of patients (Robinson, 1973b). These dyskinesias begin acutely after drug administration, occur most frequently in young patients, and consist of torticollis, trismus, facial spasms, opisthotonos, and oculogyric crises (Borenstein and Bles, 1965; Casteels-Van Daele et al., 1970; De Silva et al., 1973). They are therefore identical with acute dyskinesias produced by phenothiazine and

Address for correspondence and reprint requests: Dr Daniel Tarsy, Veterans Administration Hospital, Neurology Service, 150 South Huntington Avenue, Boston, Massachusetts 02130, U.S.A. (Accepted 3 December 1974.) butyrophenone antipsychotic drugs. The latter drugs are known to block central dopamine receptors (Andén et al., 1970) and therefore frequently produce Parkinsonism when administered chronically (Hornykiewicz, 1973). The fact that metoclopramide, like the phenothiazines and butyrophenones, produces catalepsy (Costall and Naylor, 1973) and antagonizes the behavioural effects of apomorphine and amphetamine in laboratory animals (Janssen et al., 1967; Hackman et al., 1973; Dolphin et al., 1975) indicates that it, too, may block dopamine receptors important for motor function as well as those involved in vomiting mechanisms (Peng, 1963).

Primarily because of the occurrence of acute dyskinesias, the use of metoclopramide in Parkinson's disease has been discouraged (Carter, 1973; Hildick-Smith, 1973). Strikingly, however, signs of Parkinsonism such as akinesia and rigidity have rarely been described as acute reactions to metoclopramide (Borenstein and Bles, 1965) and, to our knowledge, have not been reported after the chronic administration of this drug. In our clinic, in fact, metoclopramide is frequently used to prevent nausea and vomiting during levodopa treatment of Parkinson's disease. In a retrospective study of 40 patients who have 
received levodopa together with metoclopramide on a chronic basis (30-80 mg daily), nausea and vomiting have been prevented with no apparent deleterious effect on Parkinsonism or response to levodopa (D. Tarsy and C. D. Marsden, unpublished observations). Since significant numbers of patients with Parkinson's disease receiving levodopa may also be treated with metoclopramide, it seemed important to carry out a prospective study to determine whether it may increase Parkinsonism or interfere with the action of levodopa.

The choreiform and dystonic involuntary movements commonly produced by levodopa are probably due to a central dopaminergic effect and are readily abolished by drugs known to block dopamine receptors (Klawans and Weiner, 1974). The effect of metoclopramide on levodopainduced involuntary movements should therefore serve as an additional index of central antidopaminergic effect. For this reason, a population of patients exhibiting a high incidence of levodopa-induced involuntary movements was selected for this study. For purposes of comparison, the effect of equivalent doses of pimozide, a known blocker of central dopamine receptors (Andén et al., 1970) and promethazine, a phenothiazine antiemetic devoid of adverse extrapyramidal effects were also included in the study.

\section{METHODS}

OPEN METOCLOPRAMIDE TRIAL Twelve patients with Parkinson's disease (11 idiopathic and one postencephalitic; six men and six women; mean age 65.8 years) were selected for study. Mean duration of disease excluding the postencephalitic patient, was 9.2 years. Ten were taking levodopa (mean duration 4.1 years) to which five patients had shown a good therapeutic response. Eight patients were taking levodopa (mean daily dose $2.7 \mathrm{~g}$ ) and two were taking levodopa (mean daily dose $0.9 \mathrm{~g}$ ) combined with L-alpha-methyldopahydrazine, an extracerebral decarboxylase inhibitor. Doses of levodopa, amantadine (nine patients) and anticholinergic drugs (eight patients) were not changed during the trial. Five patients displayed levodopa-induced involuntary movements and two complained of nausea or vomiting.

Subjects were treated as outpatients with metoclopramide, $30 \mathrm{mg}$ daily given in three divided doses. Assessments for total disability, tremor, rigidity, akinesia, and posture were made at the start of treatment and at four week intervals according to a scoring method described previously (Marsden $e t$ al., 1973). Subjective impressions and adverse effects were recorded at each visit. In four patients the dose of metoclopramide was increased to $60 \mathrm{mg}$ daily, twice the normal antiemetic dose, during the last four weeks of treatment.

CONTROLLED TRIAL OF METOCLOPRAMIDE, PIMOZIDE, AND PROMETHAZINE Twenty-four patients with Parkinson's disease (23 idiopathic and one postencephalitic; 15 men and nine women; mean age

\section{TABLE 1}

TREATMENT SCHEDULE FOR CONTROLLED TRIAL

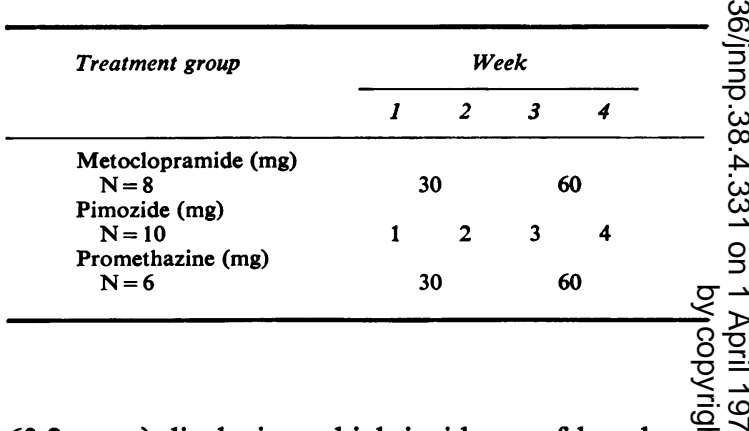

63.2 years) displaying a high incidence of levodopa 각 induced involuntary movements were chosen for study. Mean duration of disease, excluding the postencephalitic patient, was 10.3 years. All but one patient were taking levodopa (mean duration 3.4 years) and, except for five patients, had shown good therapeutic responses. Fourteen were taking levodopa (mean daily dose $2.2 \mathrm{~g}$ ) and nine were taking levodopa (mean daily dose $0.7 \mathrm{~g}$ ) combined with L-alphamethyldopahydrazine. With three exceptions, all patients on levodopa had involuntary movements. Doses of levodopa, amantadine (14 patients), and anticholinergic drugs (12 patients) were not changed during the trial.

Before treatment patients were scored for total disability, tremor, rigidity, akinesia, posture, and involuntary movements. They were then categorized as having either mild, moderate, or severe Parkinsonism and divided among three treatment groups $>$ (Table 1) to receive metoclopramide, pimozide, or promethazine. No significant difference existed N between mean total disability scores, age, duration of disease, levodopa dosage, and incidence of $\tilde{N}$ involuntary movements among the three groups $\underset{\mathrm{N}}{\mathrm{N}}$ (Student's $t$ test).

Subjects were treated as outpatients with active 
drug and matched placebo tablets for four weeks each in a cross-over sequence whereby one-half the patients in each group began with active drug and one-half began with placebo. An identical regimen of drug or placebo given in increasing doses was followed (Table 1). Each patient was assessed for total disability, disability subscores, and involuntary movements at the start of the trial and at two week intervals for eight weeks. Patients and examiners were unaware of the treatment plan used in each case. A research nursing assistant (Mrs P. Asselman) supervised medication assignments and dispensed a two weeks supply of tablets at each visit. In addition to formal assessment, patients were questioned concerning subjective impressions and adverse effects. Patients subsequently developing significant adverse effects were returned to the dose of the previous treatment period and, when possible, continued this to conclusion of the four weeks treatment period.

\section{RESULTS}

OPEN METOCLOPRAMIDE TRIAL Ten of 12 patients took metoclopramide for a sufficient period to assess its effect. Two patients were dropped from the trial; one due to hospitalization for unrelated medical illness and one because of nausea. Mean duration of treatment was 9.6 weeks (range four to 16 weeks). No significant difference was observed between mean total disability scores before $(26.9 \pm 4.4 \mathrm{SE})$ and after $(28.0 \pm 4.9 \mathrm{SE})$ metoclopramide (Student's $t$ test, paired comparison). Individual disability subscores also showed no significant change. Levodopa-induced involuntary movements which had been present in five patients before treatment remained unchanged while additional acute dyskinesias did not appear. Nausea and vomiting were abolished in both patients with this complaint, while two others reported increased appetite. Except for drowsiness in two patients, no other effects were noted. Four patients given $60 \mathrm{mg}$ daily during their last four weeks of treatment showed no significant change in Parkinsonism or other adverse effects.

CONTROLLED TRIAL OF METOCLOPRAMIDE, PIMOZIDE, AND PROMETHAZINE Metoclopramide Seven of eight patients completed the trial. One patient was dropped because of increased falling and personality change while receiving placebo. Comparison of mean total disability scores and disability subscores before treatment, after
TABLE 2

MEAN TOTAL DISABILITY SCORES AT START, AFTER PLACEBO, AND AFTER ACTIVE DRUG

\begin{tabular}{lcc}
\hline Treatment group & $\begin{array}{c}\text { Total disability } \\
\text { scores }\end{array}$ & $\begin{array}{c}\text { Levodopa-induced } \\
\text { involuntary movements }\end{array}$ \\
\hline Metoclopramide & $19.7 \pm 4.6$ & 6 \\
Start & $20.2 \pm 5.6$ & 6 \\
Placebo & $19.7 \pm 5.0 \S$ & 6 \\
Drug & & \\
Pimozide & $21.2 \pm 3.8$ & 9 \\
Start & $21.2 \pm 3.5$ & 9 \\
Placebo & $25.5 \pm 3.6 \pm$ & 4 \\
Drug & & \\
Promethazine & & 5 \\
Start & $27.4 \pm 6.0$ & 5 \\
Placebo & $29.8 \pm 8.0$ & 5 \\
Drug & $27.0 \pm 7.4 \S$ & \\
\hline
\end{tabular}

* Mean value \pm SEM. Higher score indicates greater disability.

$\dagger$ Refers to patients included in statistical analysis.

$\ddagger \mathbf{P}<0.025$. Significance of differences between paired placebo and drug periods assessed by Wilcoxon's matched-pairs signed-ranks test (Siegel, 1956). $\S \mathrm{NS}$.

placebo, and after metoclopramide showed no significant difference (Table 2). The incidence and severity of levodopa-induced involuntary movements was unchanged and acute dyskinesias did not appear. One patient complained of increased gait disturbance and a second of 'talking rubbish' while receiving metoclopramide but objective changes were not observed.

Pimozide Seven of ten patients completed the trial. One patient was dropped because of poor clinic attendance, while in two others pimozide was discontinued after two weeks because of intolerable worsening of Parkinsonism. In these two patients disability scores after two rather than four weeks of active drug were retained for statistical analysis. In two other patients the daily dose of pimozide could not be raised above $1 \mathrm{mg}$ because of increased Parkinsonism. The remaining five patients reached $4 \mathrm{mg}$ daily with signs of worsening being obvious in two cases. When mean total disability scores after pimozide were compared with those after placebo a significant increase in Parkinsonism was observed (Table 2). Disability subscores for akinesia and rigidity showed the greatest change. Subjectively, symptoms of increasing Parkinsonism were often prominent with patients reporting increased gait 
disturbance, falling, and a general 'slowing down'. Among nine patients with levodopainduced involuntary movements, various combinations of chorea, orofacial dyskinesia, and dystonia were abolished in five and significantly reduced in a sixth patient (Table 2). No change in involuntary movements occurred after placebo. In four of these six patients abolition of involuntary movements was associated with a significant increase in Parkinsonism which occurred simultaneously, while in two cases Parkinsonism did not change. Conversely, two patients showing increased Parkinsonism showed no change in involuntary movements.

Promethazine Four of six patients completed the trial. One patient completed placebo but discontinued promethazine after three weeks because of drowsiness and blurred vision; a second completed promethazine but discontinued placebo after two weeks because of nausea, gait disturbance, and increased tremor. In these two cases disability scores after two rather than four weeks of the incomplete periods were used for statistical analysis. Comparison of mean total disability scores and disability subscores before treatment, after placebo, and after promethazine showed no significant change (Table 2). The incidence and severity of levodopa-induced involuntary movements also remained unchanged.

\section{DISCUSSION}

Behavioural studies in rodents suggest that metoclopramide blocks striatal dopamine receptors with about one-tenth the potency of pimozide (Dolphin et al., 1975). The fact that metoclopramide is a potent stimulator of prolactin release in humans (McNeilly et al., 1974) is similar to the effect of phenothiazines (Turkington, 1972) and suggests blockade of dopamine receptors within the median eminence of the hypothalamus. As already indicated, metoclopramide blocks the action of apomorphine, a known dopamine receptor stimulator, in the medullary chemoreceptor trigger zone (Malméjac et al., 1964).

Drugs which block dopamine receptors, such as phenothiazines or butyrophenones, reverse the anti-Parkinsonism effect of levodopa and abolish levodopa-induced involuntary movements (Klawans and Weiner, 1974). In this study pimozide was quite potent in its ability to increase Parkinsonism and abolish levodopainduced involuntary movements, an effect similar to that of haloperidol (Klawans and Weiner, 1974). Metoclopramide, by contrast, given in larger than antiemetic doses and up to 15 times the dose of pimozide, resembled promethazine in failing to increase signs of Parkinsonism or reverse levodopa-induced involuntary movements in both a short double-blind study or the more prolonged open trial. It is interesting to note that metoclopramide is also devoid of significant antipsychotic activity (Borenstein and Bles, 1965). Since drugs which interfere with striatal dopaminergic mechanisms are usually effective as antipsychotic drugs (Andén et al., 1970; Matthysse, 1973), this too has been an unexpected finding.

The mechanism of drug-induced acute dyskinesias is unknown. Antipsychotic drugs which produce acute dyskinesias also produce Parkinsonism after chronic administration. Although this may suggest that dopamine receptor blocke $\frac{7}{0}$ ade is important for the acute dyskinesias as we as for drug induced Parkinsonism, this i $\overrightarrow{0}$ entirely speculative. The capacity of metoclo? or pramide to produce acute dyskinesias but fail to produce Parkinsonism in either normal subjects or in patients with pre-existing Parkinson's disease is a unique pharmacological property. Phenothiazines which, like metoclopramide, have antiemetic properties but do not produce Parkinsonism (such as promethazine) also do not produce acute dyskinesias.

Several simple explanations for our findings might be offered. Failure to gain access to striatal receptors in the dose used, variability in effect of metoclopramide on different central dopamine receptors, or some unrecognized pharmacological property which protects against production of Parkinsonism might be considered. This study offers indirect evidence, however, that the mechanism for drug-induced acute dyskinesias may be entirely separate from interference with striatal dopaminergic mechanisms. Recent reports that fenfluramine occasionally produces acute dystonic reactions (Sananman, 1974) which may have a pharmacological basis distinctive from catecholaminergic effects (Shoul- 
son and Chase, 1974) also suggest that druginduced acute dyskinesias are not necessarily related to blockade of dopamine receptors.

From a practical point of view, the administration of metoclopramide to prevent levodopainduced nausea or vomiting in patients with Parkinson's disease appears to be a safe practice. On the other hand, pimozide, although able promptly to reverse levodopa-induced involuntary movements, appears to be of limited usefulness for this purpose because of the equally impressive and prompt worsening of Parkinsonism which it produces.

D.T. was supported in part by the Committee to Combat Huntington's Disease, Los Angeles, California, and The Wellcome Trust. We thank Mrs P. Asselman and the pharmacy, The Maudsley Hospital, for their assistance in this study. We wish to thank Merck, Sharp, and Dohme Ltd., King's College Hospital Research Trust, and the Medical Research Council for financial support.

\section{REFERENCES}

Andén, N.-E., Butcher, S. G., Corrodi, H., Fuxe, K., and Ungerstedt, U. (1970). Receptor activity and turnover of dopamine and noradrenaline after neuroleptics. European Journal of Pharmacology, 11, 303-314.

Borenstein, P., and Bles, G. (1965). Effets cliniques et électroencéphalographiques du métoclopramide en psychiatrie. Thérapie, 20, 975-995.

Carter, S. M. (1973). Pyridoxine and Parkinsonism. British Medical Journal, 4, 491.

Casteels-Van Daele, M., Jaeken, J., Schueren, P. van der, Zimmerman, A., and Bon, P. van den (1970). Dystonic reactions in children caused by metoclopramide. Archives of Disease in Childhood, 45, 130-133.

Costall, B., and Naylor, R. J. (1973). Is there a relationship between the involvement of extrapyramidal and mesolimbic brain areas with the cataleptic action of neuroleptic agents and their clinical antipsychotic effect? Psychopharmacologia (Berl.), 32, 161-170.

De Silva, K. L., Muller, P. J., and Pearce, J. (1973). Acute drug-induced extrapyramidal syndromes. Practitioner (Lond.), 211, 316-320.

Dolphin, A., Jenner, P., Marsden, C. D., Pycock, C., and Tarsy, D. (1975). Pharmacological evidence for cerebral dopamine receptor blockade by metoclopramide in rodents. Psychopharmacologia (Berl.). (In press.)

Hackman, R., Pentikäinen, P., Neuvonen, P. J., and Vapaatalo, H. (1973). Inhibition of the apomorphine gnawing compulsion by amantadine. Experientia, 29, 1524-1525.

Hildick-Smith, M. (1973). Pyridoxine in parkinsonism. Lancet, 2, 1029-1030.

Hornykiewicz, O. (1973). Dopamine in the basal ganglia. British Medical Bulletin, 29, 172-178.

Jacoby, H. I., and Brodie, D. A. (1967). Gastrointestinal actions of metoclopramide. Gastroenterology, 52, 676-684.

Janssen, P. A. J., Niemegeers, C. J. E., Schellekens, K. H. L., and Lenaerts, F. M. (1967). Is it possible to predict the clinical effects of neuroleptic drugs (major tranquillizers) from animal data? Part 4. Arzneimittel-Forschung, 17, 841856.

Justin-Besançon, L., and Laville, C. (1964). Action antiémétique du métoclopramide vis-à-vis de l'apomorphine et de l'hydergine. Comptes Rendus des Séances de la Société de Biologie et de ses Filiales, 158, 723-727.

Klawans, H. L., Jr, and Weiner, W. J. (1974). Attempted use of haloperidol in the treatment of L-dopa induced dyskinesias. Journal of Neurology, Neurosurgery, and Psychiatry, 37, 427-430.

Laville, C. (1964). Protection exercée par le métoclopramide contre les effets vomitifs du sulfate de cuivre. PathologieBiologie (Paris), 12, 577-578.

McNeilly, A. S., Thorner, M. O., Volans, G., and Besser, G. M. (1974). Metaclopramide and prolactin. British Medical Journal, 2, 729.

Malméjac, J., Laville, C., and Margarit, J. (1964). Technique pour l'étude de l'action centrale de poisons émétiques et anti-émétiques. Comptes Rendus des Séances de la Société de Biologie et de ses Filiales, 158, 964-965.

Marsden, C. D., Parkes, J. D., and Rees, J. E. (1973). A year's comparison of treatment of patients with Parkinson's disease with levodopa combined with carbidopa versus treatment with levodopa alone. Lancet, 2, 1459-1462.

Matthysse, S. (1973). Antipsychotic drug actions: a clue to the neuropathology of schizophrenia? Federation Proceedings, 32, 200-205.

Peng, M. T. (1963). Locus of emetic action of epinephrine and dopa in dogs. Journal of Pharmacology and Experimental Therapeutics, 139, 345-349.

Robinson, O. P. W. (1973a). Metoclopramide-a new pharmacological approach? Postgraduate Medical Journal, 49, Suppl. 4, 9-12.

Robinson, O. P. W. (1973b). Metoclopramide-side effects and safety. Postgraduate Medical Journal, 49, Suppl. 4, 77-80.

Sananman, M. L. (1974). Dyskinesia after fenfluramine. New England Journal of Medicine, 291, 422.

Shoulson, I., and Chase, T. N. (1974). Fenfluramine and dyskinesias. New England Journal of Medicine, 291, 850 851.

Siegel, S. (1956). Nonparametric Statistics for the Behavioral Sciences, p. 75-83. McGraw-Hill: New York.

Turkington, R. W. (1972). Prolactin secretion in patients treated with various drugs. Archives of Internal Medicine, 130, 349-354. 